\title{
A high-throughput cheese manufacturing model for effective cheese starter culture screening
}

\author{
H. Bachmann, ${ }^{\star} \dagger \ddagger$ Z. Kruijswijk, ${ }^{*}$ D. Molenaar, ${ }^{\dagger} \dagger \ddagger$ M. Kleerebezem, ${ }^{*} \dagger \S^{1}$ and J. E. T. van Hylckama Vlieg ${ }^{*} \dagger \#$ \\ ${ }^{*}$ NIZO Food Research, PO Box 20, 6710 BA Ede, the Netherlands \\ †Kluyver Centre for Genomics of Industrial Fermentation, Delft, the Netherlands \\ ¥Vrije Universiteit Amsterdam, Systems Bioinformatics IBIVU, De Boelelaan 1085, 1081HV Amsterdam, the Netherlands \\ §Wageningen University, Laboratory for Microbiology, Wageningen, the Netherlands \\ \#Danone Research, Gut and Microbiology Platform, RD 128, 91767 Palaiseau Cedex, France
}

\begin{abstract}
Cheese making is a process in which enzymatic coagulation of milk is followed by protein separation, carbohydrate removal, and an extended bacterial fermentation. The number of variables in this complex process that influence cheese quality is so large that the developments of new manufacturing protocols are cumbersome. To reduce screening costs, several models have been developed to miniaturize the cheese manufacturing process. However, these models are not able to accommodate the throughputs required for systematic screening programs. Here, we describe a protocol that allows the parallel manufacturing of approximately 600 cheeses in individual cheese vats each with individual process specifications. Protocols for the production of miniaturized Gouda- and Cheddar-type cheeses have been developed. Starting with as little as $1.7 \mathrm{~mL}$ of milk, miniature cheeses of about $170 \mathrm{mg}$ can be produced and they closely resemble conventionally produced cheese in terms of acidification profiles, moisture and salt contents, proteolysis, flavor profiles, and microstructure. Flavor profiling of miniature cheeses manufactured with and without mixed-strain adjunct starter cultures allowed the distinguishing of the different cheeses. Moreover, single-strain adjunct starter cultures engineered to overexpress important flavor-related enzymes revealed effects similar to those described in industrial cheese. Benchmarking against industrial cheese produced from the same raw materials established a good correlation between their proteolytic degradation products and their flavor profiles. These miniature cheeses, referred to as microcheeses, open new possibilities to study many aspects of cheese production, which will not only accelerate product development but also allow a more systematic approach to investigate the complex biochemistry and microbiology of cheese making.
\end{abstract}

Received May 12, 2009.

Accepted August 28, 2009.

${ }^{1}$ Corresponding author: Michiel.Kleerebezem@nizo.nl
Key words: high throughput, cheese, manufacturing, screening

\section{INTRODUCTION}

Industrial cheese manufacturing is a process characterized by many variables. First, standardized milk is treated with an enzyme to coagulate the milk proteins. This coagulation leads to a gel-like structure, the curd, which is cut into small blocks and subsequently stirred, following a cheese-specific temperature regimen. During the stirring of the curds syneresis occurs, a process that leads to the extrusion of the liquid fraction, the whey, from the protein matrix. The whey contains a high amount of lactose and, for a typical Gouda-type cheese, a part of this lactose is removed by replacing some of the whey with water. Eventually, the curd is molded and pressed and, in the case of Gouda-type cheese, salt is added by submerging the cheese in brine. Before the initial coagulation step, a mixed culture of bacteria, the starter culture, is added to the milk. These bacteria mostly belong to the lactic acid bacteria (LAB) and they are responsible for several essential properties of cheese (Smit et al., 2005b). The acidification resulting from the conversion of lactose into lactic acid by LAB not only determines the organoleptic characteristics but also serves as a preservative that prevents the growth of other, nonstarter bacteria, which is important in terms of product quality and consistency, shelf life, and food safety. The proteolytic activity of the bacterial starter culture catalyzes the degradation of milk proteins, which influences cheese texture and results in the formation of peptides and free amino acids. Amino acids act as precursors for specific bacterial metabolites, which include potent aroma compounds. In addition to proteolysis, glycolysis and lipolysis are important pathways leading to flavor-active bacterial metabolites. Examples of such molecules resulting from carbohydrate metabolism are acetate, diacetyl, acetaldehyde, propionic acid, and acetoin. Examples of relevant flavor derivatives from amino acid metabolism are 3-methylbutanal, dimethylsulfide, 
or methional (Fox and Wallace, 1997; McSweeney and José Sousa, 2000; Yvon and Rijnen, 2001). The degradation of amino acids leading to the formation of $\alpha$-keto-acids and their further degradation to important flavor compounds has been relatively well-characterized (Yvon et al., 1997, 2000; van Kranenburg et al., 2002). The actual lysis of bacterial cells during the ripening period is also thought to have an influence on cheese properties, mainly through the release of intracellular peptidases (Roginski, 2003). In addition to the production of flavor-active molecules, the bacterial population can also influence the texture of a food product by, for example, the production of exopolysaccharides (Hassan et al., 2005) or through proteolytic activity (Lucey et al., 2003).

Given this complexity of cheese making, it is obvious that there are many combinatorial possibilities of variables, which makes the development of novel cheese variants and new production protocols cumbersome, laborious, and expensive. For example, starter cultures show a large variation in functional properties and thus, the choice of starter culture can have a major influence on the properties of the final cheese product. Adjunct or secondary starter culture microorganisms are added to certain cheeses with the purpose of improving the sensory quality (El Soda et al., 2000). The positive influence of single or mixed adjunct starter cultures on cheese properties is well-recognized (Fox et al., 1996; El Soda et al., 2000; Ayad et al., 2003; Azarnia et al., 2006) and widely applied. Consequently, the screening of strain collections and natural isolates offers an attractive approach for the identification of applicable new starter strains. Screening efforts are commonly performed in laboratory media (Smit et al., 2004; Brandsma et al., 2008) or in media designed to resemble a product environment (Crow et al., 1994; Ayad et al., 1999). Such screens yield valuable insights into strain-specific properties. However, they often have little value for predicting strain performance in cheese in which environmental conditions alter the physiological status of the cell. This is illustrated by the relatively poor correlation of volatile compounds measured from different lactococcal cultures grown either in milk or in a cheese paste model (Ayad et al., 1999). Moreover, in a recent study it was demonstrated that the specific activities of 5 lactococcal enzymes, which are considered to be of key importance for flavor formation, displayed very limited or no correlation if measured after bacterial growth in either a rich laboratory medium or a chemically defined medium (Bachmann et al., 2009). That study established that the predictive value of in vitro liquid culture screening results is very limited and strongly determined by culture conditions, indicating that high-throughput screening technologies in a product-like environment would be of great value. To the best of our knowledge, the smallest model system reported for cheese manufacturing uses $200 \mathrm{~mL}$ of milk per cheese and allows an approximate throughput of 10 individual cheeses per person per day (Shakeel-Ur-Rehman et al., 1998). Other model systems, which try to mimic the cheese environment, have similar limitations in their throughput capacities. For a review on cheese model systems, see Shakeel-Ur-Rehman et al. (2001). However, the described models are not effective enough and require considerable investments when applied in more elaborate or large-scale screening efforts. Current product development is therefore driven mainly by educated guesses rather than by the systematic screening of processing conditions and starter cultures. Here, we present a high-throughput cheese-making model that allows the simultaneous manufacturing of individual miniature cheeses from as little as $1.7 \mathrm{~mL}$ of milk, enabling an experienced person to handle up to 600 cheeses per day. We demonstrate the modification of flavor profiles by adding either a mixed-strain adjunct starter culture or single strain adjuncts, which were engineered to overexpress key enzymes involved in flavor formation. Furthermore, the results establish that the manufacturing process is highly reproducible and that key properties of the microcheeses resemble those of conventionally manufactured cheese.

\section{MATERIALS AND METHODS}

\section{Milk, Enzymes, Starter Cultures, and Culture Conditions}

The milk used for manufacturing microcheese was standardized bovine milk with a fat content of approximately $3.5 \%$, protein content of approximately $3.4 \%$ and a lactose content of approximately $4.5 \%$ (heat treated at $72.5^{\circ} \mathrm{C}$ for $9 \mathrm{~s}$ ). To allow the manufacture of cheese on different days with the same batch of milk, 800-mL aliquots were shock frozen by slowly pouring milk directly into liquid nitrogen. Subsequently, aliquots were stored at $-40^{\circ} \mathrm{C}$ until usage. Starter cultures for Gouda type cheese - FR18, Bos, and APS - were obtained from CSK Food Enrichment (Ede, the Netherlands). Starter cultures for Cheddar-type cheese-Choozit RA21 LYO 250 DCU (named RA21 throughout this paper) and Choozit FLAV54 LYO 5D (named Flav54 throughout this paper) - were obtained from Danisco (Copenhagen, Denmark). Because of the small quantities of starter culture needed, the concentrated cultures were not added directly to the milk but were precultured in sterilized, reconstituted skimmed milk powder (Promex Spray 1\% skimmed milk powder, Friesland Foods butter, Lochem, the Netherlands). For preculturing, the starter cultures 
Table 1. Strains and plasmids used to assess the effect of varying branched-chain $\alpha$-keto acid decaboxylase (bckad) and cystathionine $\beta$-lyase $(m e t C)$ expression levels on flavor profiles

\begin{tabular}{|c|c|c|}
\hline Name & Description & Reference \\
\hline \multicolumn{3}{|l|}{ Strain } \\
\hline MG1363 & Lactococcus lactis; plasmid free, wildtype strain & Gasson, 1983 \\
\hline NZ9000 & L. lactis MG1363; pepN::nisRK & Kuipers et al., 1998 \\
\hline B2083 & $\begin{array}{l}\text { Tet }^{\mathrm{r}}, \mathrm{Ery}^{\mathrm{r}}, \mathrm{Cm}^{\mathrm{r}} \text {; pGh9:ISSI integrated in the chromosome of B1157 at position } 462 \\
\text { of the decarboxylase gene (bckad) }\end{array}$ & Smit et al., 2005a \\
\hline \multicolumn{3}{|c|}{ 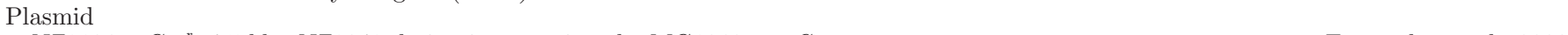 } \\
\hline
\end{tabular}

were grown under the following conditions: $20 \mathrm{~h}$ at $20^{\circ} \mathrm{C}$ for FR18 and Bos, $16 \mathrm{~h}$ at $37^{\circ} \mathrm{C}$ for APS, $18 \mathrm{~h}$ at $30^{\circ} \mathrm{C}$ for RA21, and $16 \mathrm{~h}$ at $37^{\circ} \mathrm{C}$ for Flav54. Determination of bacterial colony-forming units in cheese was done by dissolving cheese in $2 \%$ sodium citrate and subsequent plating on M17 agar (Merck, Darmstadt, Germany) supplemented with $0.5 \%$ lactose. As a control sample for GC-MS analysis, a young Gouda-type cheese (Jonge Beemster) was purchased at a local store.

\section{BcKAD and MetC Mutant Strains}

Lactococcus lactis MG1363 (Gasson, 1983), a branched-chain $\alpha$-keto acid decaboxylase (bckad) overexpression strain NZ9000 pNZ7500 (Smit et al., 2005a), a wildtype strain with high BcKAD activity L. lactis B1157 (Ayad et al., 1999), and its cognate bckad deletion mutant B2083 (Smit et al., 2005a), a cystathionine $\beta$-lyase ( $\boldsymbol{m e t} \boldsymbol{C}$ ) overexpression strain NZ9000 pNZ8136 (Fernandez et al., 2000), and a met $C$ deletion mutant MG1363 $\Delta$ met $C$ were used as adjunct cultures (Table 1). Strains were precultured overnight at $30^{\circ} \mathrm{C}$ in $\mathrm{M} 17$ (Oxoid Ltd., Basingstoke, UK) supplemented with $0.5 \%$ glucose. For overexpression of bckad and metC, the overnight cultures were diluted $(1: 10)$ in reconstituted skimmed milk supplemented with $0.5 \%$ glucose and incubated for $1 \mathrm{~h}$ at $30^{\circ} \mathrm{C}$. If required, $5 \mathrm{ng}$ of nisin was added per milliliter of culture and cells were incubated for another $2 \mathrm{~h}$ at $30^{\circ} \mathrm{C}$. Fifty microliters of these cultures were used as adjunct culture to $1.7 \mathrm{~mL}$ of milk, which was already inoculated with $1 \%$ of a Bos starter culture. The colony-forming units of adjunct added to the individual microcheeses were determined to be approximately $2 \times 10^{7}$ per $\mathrm{mL}$ of milk. Subsequently, Gouda-type microcheeses were manufactured essentially as described as follows. To microcheeses made with strains MG1363 and NZ9000 as adjunct, $0.5 \%$ glucose was added to the milk to allow growth of these lactose-negative strains.

\section{Production of Gouda-Type Cheese}

For cheese manufacturing, the frozen milk was thawed and subsequently warmed to $30.5^{\circ} \mathrm{C}$. The milk was supplemented with renneting enzyme (Kalase, 150 IMCU, CSK Food Enrichment) at a concentration of $230 \mu \mathrm{L} / \mathrm{L}$ of milk. Furthermore, $400 \mu \mathrm{L}$ of a $33 \%$ (wt/ vol) $\mathrm{CaCl}_{2}$ solution was added per liter of milk. As a starter culture, $1 \%$ of an FR18 preculture was added to the milk. For microcheeses produced with an adjunct culture, $2.5 \%$ of an APS preculture was added to the milk. Following inoculation, the wells of a $2-\mathrm{mL}$ deep-well microplate (Greiner, Alphen a/d Rijn, the Netherlands) were filled with $1.7 \mathrm{~mL}$ of milk each and the plates were sealed with a capmat (Greiner) and incubated at $30.5^{\circ} \mathrm{C}$. After $45 \mathrm{~min}$, the cutting of the curds was begun using a custom-made stirring device (Figure 1). This stirring device was made from stainless steel and consisted of a plate with a handle at the top and 96 pins attached to the bottom. The pins were $3 \mathrm{~mm}$ in diameter and $45 \mathrm{~mm}$ long, and they were aligned in such a way that they were positioned precisely in the middle of each well when the stirring device was placed in a 96-well microplate (Figure 1). The stirring device was used for manual cutting and stirring of the curds. Cutting of the curds was carried out by slow horizontal and vertical movements of the stirring device through the curds. This was followed by stirring of the curds and the 2 steps together took 20 min. During these $20 \mathrm{~min}$, cutting/stirring for $20 \mathrm{~s}$ and resting for $3 \mathrm{~min}$ were alternated. After stirring, the curds were allowed to rest for $5 \mathrm{~min}$ and then the plates were sealed again and centrifuged at $466 \times g$ for $5 \mathrm{~min}$ to slightly compact the curds. Subsequently, $680 \mu \mathrm{L}$ of whey was removed from each well and replaced with $620 \mu \mathrm{L}$ of sterile tap water. Throughout the cutting, stirring, and centrifuging steps, the plates were kept at $30.5^{\circ} \mathrm{C}$. The addition of the washing water, which was heated to $45^{\circ} \mathrm{C}$, brought the temperature in the wells to approximately $36^{\circ} \mathrm{C}$. After addition of the water, the plates were placed in a water bath at $35.5^{\circ} \mathrm{C}$ and the curds were resuspended with the stirring device. This was followed by a 40 min incubation period at $35.5^{\circ} \mathrm{C}$ and regular stirring as described above. Then, the plates were incubated at the same temperature for another $20 \mathrm{~min}$ without stirring. Whey was removed 
from the curds by centrifuging the microplates at 4,800 $\times g$ for $1 \mathrm{~h}$ at $30^{\circ} \mathrm{C}$. The supernatant was discarded by decanting the plate and keeping the plate upside down on a tissue for 15 min. Finally, the plates where covered with a Breathseal (Greiner) and placed in a climate stove at $30^{\circ} \mathrm{C}$ and $30 \%$ relative humidity to adjust the moisture content of the microcheeses. After overnight incubation in the climate stove, $17 \mu \mathrm{L}$ of a sterile $20 \%$ sodium chloride solution (wt/vol) was added to each well which, as calculated from the expected yield (Van Slyke and Price, 1949), should give approximately $3 \%$ salt in dry matter in the cheese. The evaluation of moisture content of the microcheeses was monitored by calculations based on the total weight of the cheese in each plate and by taking individual samples and determining the moisture content as described below. After cheeses reached the target moisture content of 42 to $45 \%$, the plates were sealed in 0.8 atmospheres of $100 \%$ nitrogen. The cheeses were left to ripen at $17^{\circ} \mathrm{C}$ for 7 and $42 \mathrm{~d}$ before further analysis.

\section{Production of Cheddar-Type Cheese}

The ingredients for Cheddar-type cheese (milk, Kalase, and $\mathrm{CaCl}_{2}$ ) were used in concentrations identical to that for Gouda type cheese. A 1\% preculture of RA21 was used as starter culture for Cheddar. In case of the addition of an adjunct next to RA21, $0.75 \%$ of Flav54 preculture was added. After inoculation, the plates were sealed and incubated at $30^{\circ} \mathrm{C}$ for $45 \mathrm{~min}$. The coagulated milk was cut and stirred with the cutting device for $10 \mathrm{~min}$ as described above. Subsequently, stirring was continued and the temperature was increased by $1^{\circ} \mathrm{C}$ per $6 \mathrm{~min}$ to $39^{\circ} \mathrm{C}$. The increase in temperature in this protocol was relatively slow, which ensured an equal temperature increase throughout the plate. Then, stirring was continued for another $60 \mathrm{~min}$ at $39^{\circ} \mathrm{C}$. Afterward, the curds were allowed to rest for $10 \mathrm{~min}$, which was followed by centrifugation of the plates at $466 \times g$ for $5 \mathrm{~min}$ at $30^{\circ} \mathrm{C}$. After centrifugation, the whey was removed and the sealed plate was incubated for another $90 \mathrm{~min}$ at $30^{\circ} \mathrm{C}$. Then, $30 \mu \mathrm{L}$ of a sterile $30 \%$ (wt/vol) sodium chloride solution was added to each well and the plates were kept at $30^{\circ} \mathrm{C}$ for another 5 min. Subsequently the plates were centrifuged at 4,800 $\times g$ and $30^{\circ} \mathrm{C}$ for $60 \mathrm{~min}$. The removal of supernatant, reduction of the moisture content, and ripening conditions were performed as described. The target moisture content was 35 to $38 \%$.

\section{Comparison of Industrial Cheese and Microcheese}

Cheese was manufactured on a pilot scale essentially as described earlier (Kammerlehner, 1989; Ledeboer et

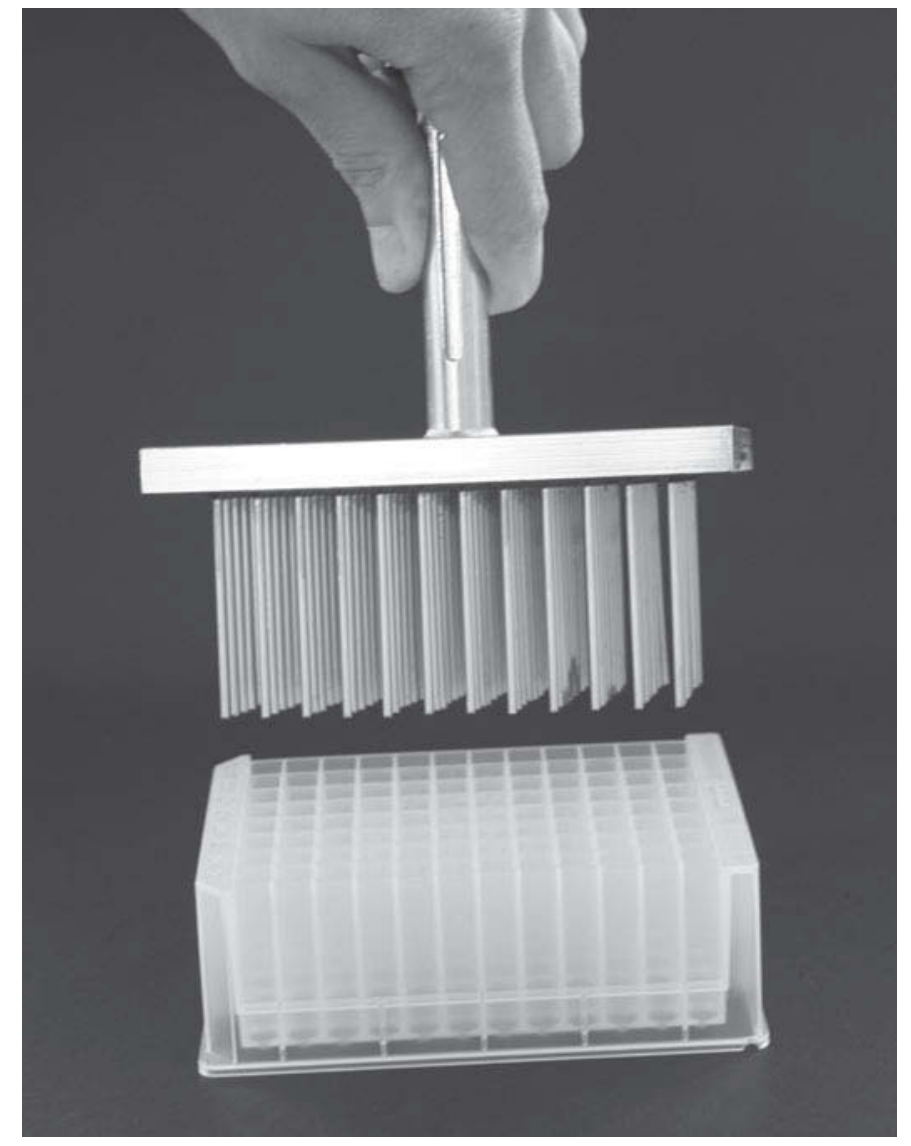

Figure 1. Microplate and stirring device used for the manufacturing of 96 individual microcheeses.

al., 2002). In brief, curds were prepared in a 1,500-L open vat and eventually shaped into $10-\mathrm{kg}$ wheels. After milk inoculation with Bos starter culture, an aliquot was taken from the 1,500-L vat and used immediately for further processing according to the Gouda-type microcheese protocol. Pilot-scale cheeses and microcheeses were ripened at $13^{\circ} \mathrm{C}$, and samples were taken after 14 , 41, and $124 \mathrm{~d}$.

\section{Physicochemical Analysis}

Moisture, salt, and fat analysis were performed according to the Dutch standards NEN 3755, 3762, and 3758 (Nederlands Centrum voor Normalizatie, Delft, the Netherlands), respectively, except that, for each determination, only approximately $170 \mathrm{mg}$ of cheese (one microcheese) was used. For the butyrometric fat determination, 15 microcheeses were pooled to yield sufficient material $(>2 \mathrm{~g})$. The $\mathrm{pH}$ values were determined with a $3-\mathrm{mm} \mathrm{pH}$ electrode (BioTrode, Metrohm, Herisau, Switzerland), which was used according to the manufacturer's instructions. For $\mathrm{pH}$ measurements in 
microcheese, this electrode was pressed approximately $2 \mathrm{~mm}$ into the microcheese.

\section{Analysis of Proteolysis}

Determination of proteolysis in microcheese samples was performed essentially as described elsewhere (Visser et al., 1991). In brief, $170 \mathrm{mg}$ of cheese was dissolved in $1.5 \mathrm{~mL}$ of buffer $\mathrm{E}^{+}\{0.1 M$ 1.3-bis[tris(hydroxymethyl)methylamino]propane, $8 \mathrm{M}$ urea, $1.3 \%$ sodium citrate $\times 2 \cdot \mathrm{H}_{2} \mathrm{O} \mathrm{pH} 7$, and $40 \mathrm{mg} / \mathrm{mL}$ dithiothreitol, which was added directly before buffer usage followed by ultrasonic treatment for $30 \mathrm{~min}$. Subsequently, $500 \mu \mathrm{L}$ was mixed with $1,500 \mu \mathrm{L}$ of elution buffer A (see below), centrifuged for $5 \mathrm{~min}$ at $17,200 \times g$, and finally filtered through a $0.22-\mu \mathrm{m}$ membrane. Analytical reversedphase chromatography (RP-HPLC) was carried out with equipment as described earlier (Visser et al., 1991). The equipment was linked to a data acquisition and processing system (Turbochrom, Perkin-Elmer, Waltham, MA). Solvent A was a mixture of acetonitrile-watertrifluoracetic acid (20:980:1, vol/vol/vol) and solvent B contained the same components (900:100:0.8, vol/vol/ vol). Components were eluted with a linear gradient of solvent B in A. The absorbance of the eluent was monitored at $220 \mathrm{~nm}$ and $280 \mathrm{~nm}$. The injection volume was $100 \mu \mathrm{L}$.

\section{GC-MS Analysis}

For volatile analysis, an Ultrafast GC-MS setup was used. Each microcheese was transferred to a $1.5-\mathrm{mL}$ headspace vial. Headspace volatiles were allowed to equilibrate for $20 \mathrm{~min}$ at $60^{\circ} \mathrm{C}$ and subsequently directly injected into the GC-MS by a Combi Pal Autosampler (CTC Analytics AG, Zwingen, Switzerland; GC column UFM RTX 200, $10 \mathrm{~m} \times 0.14 \mathrm{~mm}$; Thermo Fisher Scientific Inc., Waltham, MA). The initial temperature of the GC column was held for 0.4 min at $20^{\circ} \mathrm{C}$ and then increased at $200^{\circ} \mathrm{C} / \mathrm{min}$ to a final temperature of $250^{\circ} \mathrm{C}$ at which it was held for $0.5 \mathrm{~min}$. The total run time, including cooling, was approximately 5 min. Mass spectra were recorded by a Thermo-plus time-of-flight mass spectrometer (Thermo Fisher Scientific Inc.). The detection of mass spectra was performed with ionization energy of $70 \mathrm{eV}$ and a scanning rate of 25 scans/s. The detected $m / z$ ratio ranged from 35 to 350 . Peak identification was done using the NIST MS search program version 2.0. Quantitation of peak areas was performed using XCalibur 1.4SR1 software (Thermo Fisher Scientific Inc.).

Headspace volatiles of samples with bckad and metC mutant $L$. lactis strains as well as samples for the comparison of industrial cheese with microcheese were analyzed essentially as described above but equilibration was performed for $16 \mathrm{~min}$ at $60^{\circ} \mathrm{C}$ followed by focusing and cryofixation at $-50^{\circ} \mathrm{C}$. Separation of the compounds was performed on a FactorFour VF-1ms column $(30 \mathrm{~m} \times 0.25 \mathrm{~mm}$; Varian, Palo Alto, CA).

\section{Confocal Laser Scanning Microscopy}

Imaging was performed using a Leica TCS SP confocal laser scanning microscope (CSLM, Leica, Rijswijk, the Netherlands) in the fluorescence, single photon mode. The set-up was configured with an inverted microscope (model DM IRBE, Leica) and an Ar/Kr laser. The objective lens used was a $63 \times / \mathrm{NA1} .2 /$ water immersion/ Pl Apo (Leica). Nile Blue A (Sigma, Zwijndrecht, the Netherlands) was used to stain the inclusion of lipids in the cheese matrix.

\section{Statistical Analysis}

Clustering and analysis of correlation of the compound data of all GC-MS profiles with ripening periods and starter composition was performed using random forest (Breiman, 2001) as implemented in the Random Forest package for R (R-Development Core Team, 2008). Pearson correlation coefficients of the logarithm of the peak areas were calculated for the comparison of factory and microcheese flavor profiles.

\section{RESULTS}

\section{Development of the Small-Scale Cheese Model}

A protocol for the high-throughput manufacturing of cheese was developed by employing a standard 96-deep-well microplate as an array of cheese vats. In this method, each well can be addressed separately with substrate, ingredients, or cultures and an individual cheese is produced from as little as $1.7 \mathrm{~mL}$ of milk. For validation of the model, 4 types of cheese were prepared, encompassing Gouda- and Cheddar-type cheeses with and without adjunct starter cultures. For each of the 4 types of cheese, $2 \times 96$ microcheeses were manufactured in individual experiments, and multiple samples were analyzed for acidification rates, moisture content, salt concentration, and volatile flavor compounds. The analysis of volatile flavor compounds was performed on microcheese ripened for 7 and $42 \mathrm{~d}$. The amounts of rennet, $\mathrm{CaCl}_{2}$, and starter culture added to the milk as well the temperature regimen followed throughout cheese manufacturing were identical to those applied in conventional cheese-making protocols. The cutting of the curds with a dedicated cutting/stirring device (Figure 1) resulted in a curd size of 0.2 to $0.4 \mathrm{~mm}$ in 


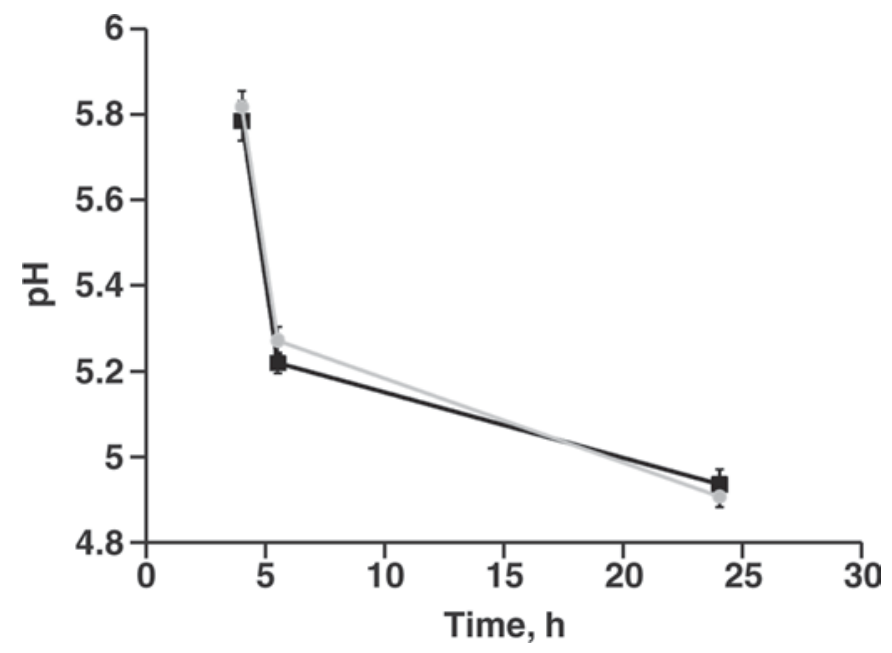

Figure 2. Acidification profiles in border wells and nonborder wells show no significant positional effects. Gray circles show $\mathrm{pH}$ values measured in various nonborder wells (positions B2 to $\mathrm{G} 11 ; \mathrm{n}=15$ ); black squares show $\mathrm{pH}$ values in border wells $\mathrm{C} 1, \mathrm{~F} 1, \mathrm{H} 2, \mathrm{H} 6$, and $\mathrm{H} 12$. Error bars show standard deviation.

diameter for Gouda type cheese and curds 0.9 to 1.1 $\mathrm{mm}$ in diameter for Cheddar-type cheese. Industrially manufactured cheeses typically show curd sizes between 5 and $10 \mathrm{~mm}$. The relatively small curd size in the presented model is inherent to the system, with the size of the cheese vats being $7 \times 7 \times 40 \mathrm{~mm}$. The pressing of the curds was mimicked by centrifugation. The addition of salt to either Gouda or Cheddar-type cheese was not performed by submerging the cheese in brine or kneading the salt into the curds, respectively, but by adding a defined amount of brine to the cheese, which was subsequently absorbed in the curd. To avoid positional effects in the individual wells of the microplate, which may be caused by temperature gradients, the milk was kept at the desired temperature during the filling of the wells and a strict temperature regimen was employed.

\section{Physicochemical Parameters}

Positional effects are a well-documented cause of artifacts in microplate screening (Malo et al., 2006). Therefore, we assessed whether there was a positional effect on the acidification profile. The $\mathrm{pH}$ in different positions of a microplate was measured 4, 5.5, and $24 \mathrm{~h}$ after the start of the microcheese manufacturing, which was defined by the moment of inoculation of milk with enzymes and starter culture. The $\mathrm{pH}$ values measured in wells on the outside borders of the plate were compared with the $\mathrm{pH}$ values measured in wells that were more centrally located. For none of the assessed time points was a significant difference detected, indicating homogeneous conditions across the entire plate during cheese manufacturing (Figure 2). Overall, the acidification rates for Gouda- and Cheddar-type cheeses showed very low standard deviations within a single experiment $(<1.2 \%)$ and remained reasonably low $(<2.9 \%)$ when comparing experiments carried out on different days (Figure 3). The measured acidification rates were very similar to the acidification profiles measured during the industrial cheese-making process (Roginski, 2003).

The moisture content measured after the last centrifugation step of the respective protocol for Gouda and Cheddar microcheeses were between 45 and $50 \%$. Based on typical moisture contents of industrial cheeses, the target moisture contents were set to 42 to $45 \%$ for
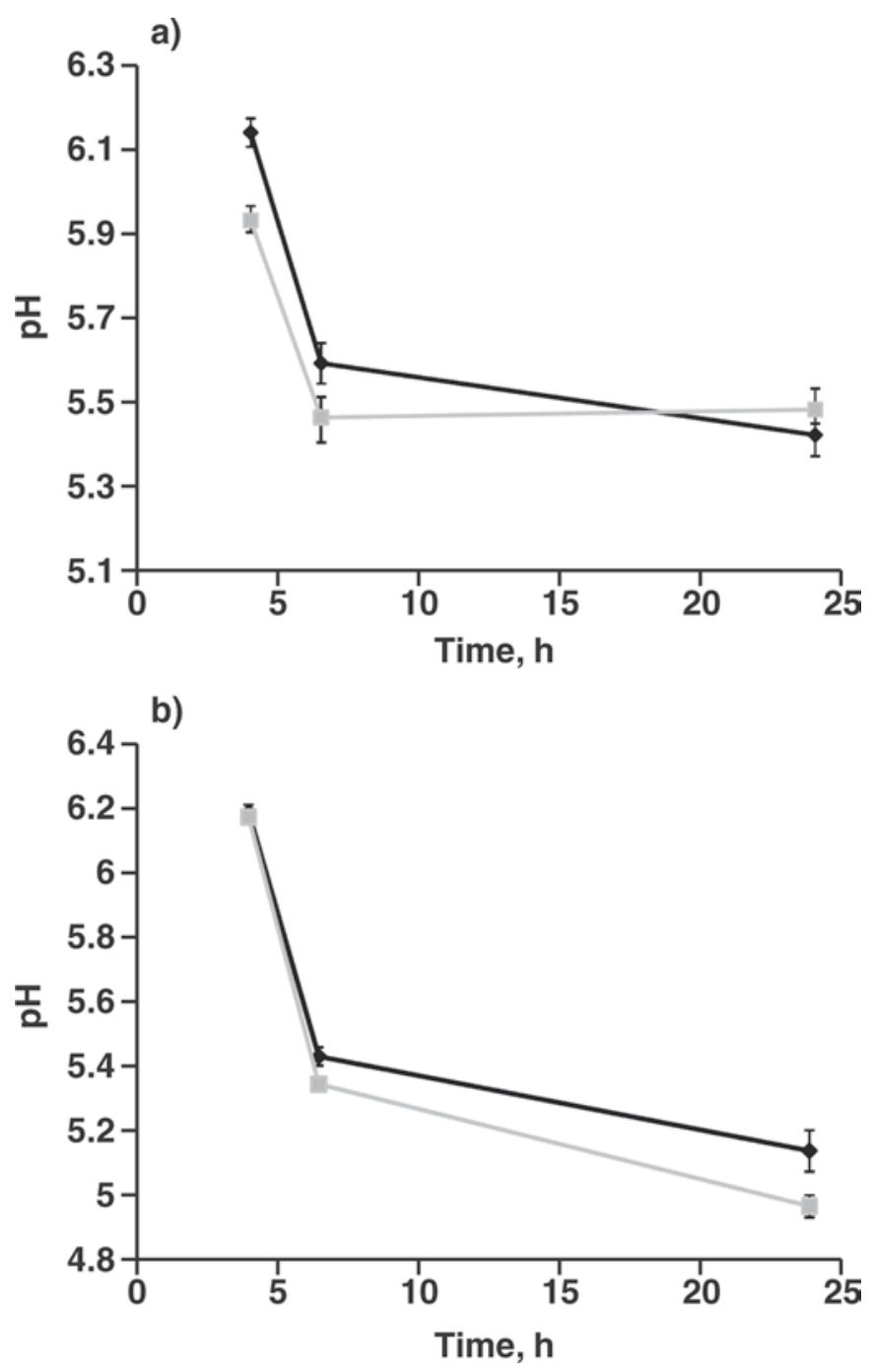

Figure 3. Acidification of Gouda (panel A) and Cheddar (panel B) type microcheese during the first $24 \mathrm{~h}$ illustrate the reproducibility between individually manufactured microcheeses. Diamonds and squares represent microcheeses made on different days. Error bars show standard deviation (for each data point, $\mathrm{n}=10$ ). 


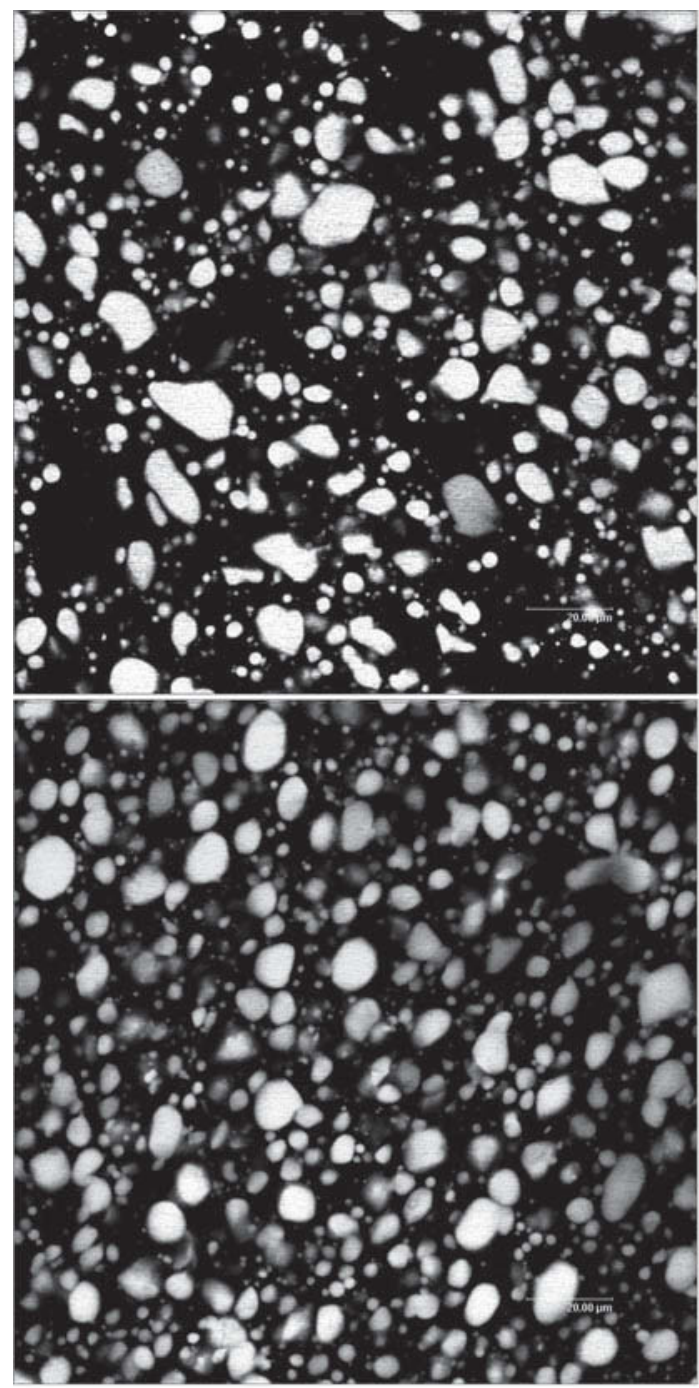

A

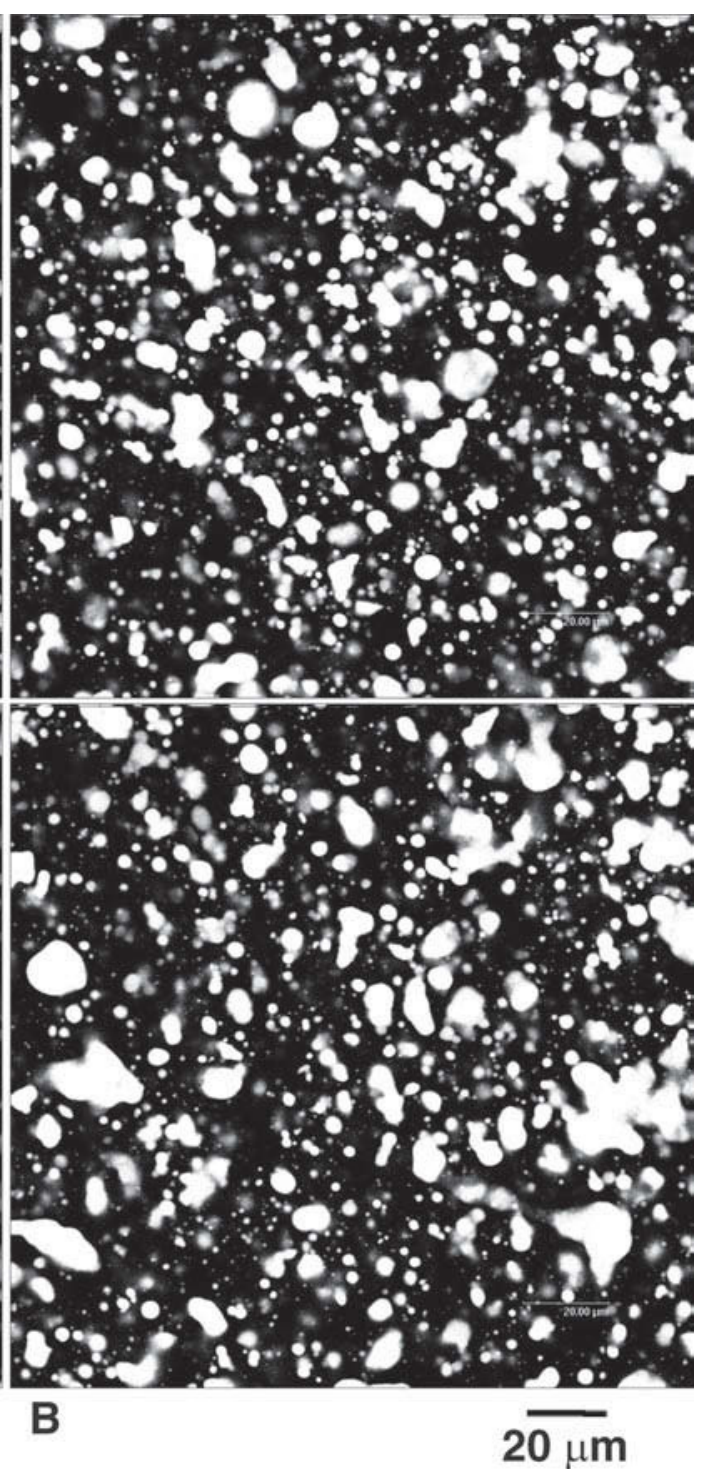

Figure 4. Comparative analysis of cheese microstructure: confocal laser scanning microscopy images of a 35-d-old Gouda-type microcheese (panel A) and an industrially manufactured 35-d-old Gouda-type cheese (panel B) show a highly similar coalescence pattern. The cheese was stained with Nile Blue to visualize the lipid inclusions (white) in the cheese matrix. Each panel shows 2 images from different sections of the preparations.

Gouda-type cheeses and 35 to $38 \%$ for Cheddar-type cheeses. To adjust the moisture content of microcheeses after centrifugation, the plates were incubated in a controlled climate stove. After $40 \mathrm{~h}$ of incubation in the climate stove, the average moisture content was $42.8 \%$ $( \pm 1.9)$ and $44.2 \%( \pm 0.7)$ for the Gouda-type microcheeses produced on different days and $40.6 \%( \pm 2.7)$ and $41.6 \%( \pm 1.7)$ for Cheddar-type microcheeses produced on different days. The Cheddar-type cheeses were incubated in the climate stove for an additional 24 $\mathrm{h}$ to achieve the target values. Following the moisture content adjustment, microcheese plates were sealed in a nitrogen atmosphere to avoid fungal contamination and ripened at $17^{\circ} \mathrm{C}$ until further analysis. The addition of salt to the microcheese was achieved by adding a defined amount of sterile brine to each cheese. Salt readily diffuses throughout cheese (Simal et al., 2001), which, because of the small size of the manufactured cheeses, will rapidly lead to a homogeneous distribution. Based on industrial cheese properties, the target values for the salt concentrations were $3 \%$ salt in dry matter for both types of cheese. The amounts of sodium chloride added were calculated to achieve the concentration found in the corresponding industrial-cheese protocol. For a Gouda-type cheese, this is readily predictable, because the total amount of the added brine remains in each 
Table 2. Gas chromatography-mass spectrometry peak areas of volatile compounds identified in microcheeses made with different starter cultures and aged for 7 or $42 \mathrm{~d}^{1}$

\begin{tabular}{|c|c|c|c|c|}
\hline \multirow{2}{*}{$\begin{array}{l}\text { Starter culture/ } \\
\text { volatile compound }\end{array}$} & \multicolumn{2}{|c|}{$7 \mathrm{~d}$} & \multicolumn{2}{|c|}{$42 \mathrm{~d}$} \\
\hline & Mean peak area & $\mathrm{SD}, \%$ & Mean peak area & $\mathrm{SD}, \%$ \\
\hline Starter culture $\operatorname{Fr} 18$ & \multicolumn{2}{|c|}{$(\mathrm{n}=4)$} & \multicolumn{2}{|c|}{$(\mathrm{n}=10)$} \\
\hline 2-Propanon & 138,651 & 18.5 & $6,751,524$ & 20.4 \\
\hline Acetic acid & 17,886 & 25.4 & 26,834 & 48.7 \\
\hline Diacetyl & 314,425 & 5.1 & 255,557 & 24.2 \\
\hline 3-Methylbutanal & 5,183 & 39.2 & 41,216 & 68.2 \\
\hline 2 Pentanone & 36,095 & 8.4 & 102,737 & 49.4 \\
\hline Butanoic acid & 1,043 & 42.0 & 196,074 & 91.2 \\
\hline Acetoin & $1,726,033$ & 18.4 & $1,643,147$ & 12.5 \\
\hline Ethylbutyrate & 643 & 31.0 & 17,162 & 128.1 \\
\hline Undecane 5,5-dimethyl & 1,416 & 30.4 & 2,193 & 59.9 \\
\hline Pentamethylheptane & 3,514 & 13.2 & 19,684 & 63.2 \\
\hline Limonene & 1,911 & 15.2 & 1,607 & 43.6 \\
\hline 2-Heptanone & 15,413 & 24.7 & 61,117 & 55.2 \\
\hline Hexanoic acid & 1,566 & 20.1 & 77,826 & 92.0 \\
\hline Ethylcaproate & 350 & 24.2 & 11,742 & 107.0 \\
\hline 2-Nonanone & 3,271 & 17.0 & 28,066 & 75.3 \\
\hline Octanoic acid & 8,687 & 17.1 & 14,457 & 37.3 \\
\hline Ethyloctanoate & 42 & 71.1 & 4,249 & 105.6 \\
\hline Starter culture Fr18APS & \multicolumn{2}{|c|}{$(\mathrm{n}=4)$} & \multicolumn{2}{|c|}{$(\mathrm{n}=10)$} \\
\hline 2-Propanon & 105,316 & 14.2 & $5,970,845$ & 15.2 \\
\hline Acetic acid & 22,288 & 57.0 & 40,426 & 47.6 \\
\hline Diacetyl & 725,639 & 9.7 & 342,150 & 13.2 \\
\hline 3-Methylbutanal & 15,283 & 51.0 & 49,207 & 57.9 \\
\hline 2 Pentanone & 20,573 & 23.7 & 102,119 & 56.7 \\
\hline Butanoic acid & 970 & 22.6 & 128,588 & 79.4 \\
\hline Acetoin & $3,504,683$ & 26.9 & $2,099,108$ & 10.8 \\
\hline Ethylbutyrate & 1,618 & 33.8 & 13,168 & 113.6 \\
\hline Undecane 5,5-dimethyl & 2,396 & 90.1 & 4,065 & 49.6 \\
\hline Pentamethylheptane & 3,668 & 8.2 & 19,861 & 41.6 \\
\hline Limonene & 1,466 & 16.7 & 1,193 & 48.0 \\
\hline 2-Heptanone & 18,410 & 69.2 & 57,348 & 60.3 \\
\hline Hexanoic acid & 1,418 & 24.9 & 46,774 & 101.0 \\
\hline Ethylcaproate & 3,262 & 60.2 & 7,007 & 99.8 \\
\hline 2-Nonanone & 8,566 & 123.7 & 21,712 & 81.4 \\
\hline Octanoic acid & 8,032 & 21.1 & 11,310 & 52.1 \\
\hline Ethyloctanoate & $\mathrm{ND}^{2}$ & & 2,352 & 120.4 \\
\hline Starter culture RA21 & \multicolumn{2}{|c|}{$(\mathrm{n}=8)$} & \multicolumn{2}{|c|}{$(\mathrm{n}=10)$} \\
\hline 2-Propanon & 190,791 & 85.6 & $7,206,944$ & 16.8 \\
\hline Acetic acid & 59,757 & 33.5 & 67,595 & 19.4 \\
\hline Diacetyl & 753,509 & 28.5 & 448,036 & 40.8 \\
\hline 3-Methylbutanal & 5,926 & 39.4 & 51,339 & 119.8 \\
\hline 2 Pentanone & 59,965 & 104.9 & 145,937 & 66.3 \\
\hline Butanoic acid & 2,405 & 17.3 & 18,159 & 40.7 \\
\hline Acetoin & $6,709,909$ & 13.2 & $2,747,033$ & 10.6 \\
\hline Ethylbutyrate & 4,517 & 26.2 & 18,738 & 122.7 \\
\hline Undecane 5,5-dimethyl & 4,226 & 87.1 & 3,840 & 51.2 \\
\hline Pentamethylheptane & 37,970 & 89.1 & 123,570 & 63.2 \\
\hline Limonene & 1,082 & 31.2 & 999 & 75.6 \\
\hline 2-Heptanone & 16,613 & 80.7 & 75,339 & 69.2 \\
\hline Hexanoic acid & 1,850 & 22.5 & 3,576 & 29.7 \\
\hline Ethylcaproate & 1,379 & 60.4 & 6,837 & 80.8 \\
\hline 2-Nonanone & 5,800 & 63.4 & 16,981 & 64.8 \\
\hline & 6.523 & 14.8 & 6.324 & 39.2 \\
\hline \multirow[t]{2}{*}{ Ethyloctanoate } & 37 & 114.4 & 318 & 65.8 \\
\hline & & & & Con \\
\hline
\end{tabular}


Table 2 (Continued). Gas chromatography-mass spectrometry peak areas of volatile compounds identified in microcheeses made with different starter cultures and aged for 7 or $42 \mathrm{~d}$

\begin{tabular}{|c|c|c|c|c|}
\hline \multirow{2}{*}{$\begin{array}{l}\text { Starter culture/ } \\
\text { volatile compound }\end{array}$} & \multicolumn{2}{|c|}{$7 \mathrm{~d}$} & \multicolumn{2}{|c|}{$42 \mathrm{~d}$} \\
\hline & Mean peak area & $\mathrm{SD}, \%$ & Mean peak area & $\mathrm{SD}, \%$ \\
\hline Starter culture RA21FLAV54 & \multicolumn{2}{|c|}{$(\mathrm{n}=8)$} & \multicolumn{2}{|c|}{$(\mathrm{n}=10)$} \\
\hline 2-Propanon & 302,558 & 42.7 & $7,268,759$ & 24.7 \\
\hline Acetic acid & 247,777 & 21.4 & 131,222 & 16.1 \\
\hline Diacetyl & 652,528 & 10.6 & 356,259 & 11.7 \\
\hline 3-Methylbutanal & 10,828 & 41.5 & 22,409 & 29.8 \\
\hline 2 Pentanone & 59,182 & 105.8 & 147,077 & 60.4 \\
\hline Butanoic acid & 2,270 & 12.1 & 24,108 & 61.9 \\
\hline Acetoin & $6,112,486$ & 7.4 & $2,729,263$ & 8.1 \\
\hline Ethylbutyrate & 3,913 & 13.0 & 22,796 & 102.0 \\
\hline Undecane 5,5-dimethyl & 8,425 & 14.2 & 2,936 & 26.4 \\
\hline Pentamethylheptane & 130,139 & 109.7 & 194,199 & 61.7 \\
\hline Limonene & 1,285 & 31.6 & 828 & 52.9 \\
\hline 2-Heptanone & 14,157 & 86.0 & 72,808 & 57.0 \\
\hline Hexanoic acid & 1,812 & 15.8 & 3,123 & 53.4 \\
\hline Ethylcaproate & 1,883 & 37.1 & 7,933 & 72.0 \\
\hline 2-Nonanone & 5,124 & 76.3 & 17,891 & 55.5 \\
\hline Octanoic acid & 5,712 & 32.2 & 6,446 & 53.8 \\
\hline Ethyloctanoate & 66 & 72.6 & 411 & 86.7 \\
\hline \multicolumn{3}{|l|}{ Starter culture Beemster } & \multicolumn{2}{|c|}{$(\mathrm{n}=4)$} \\
\hline 2-Propanon & & & 230,998 & 16.6 \\
\hline Acetic acid & & & 41,126 & 14.5 \\
\hline Diacetyl & & & 48,245 & 23.0 \\
\hline 3-Methylbutanal & & & 14,781 & 24.6 \\
\hline 2 Pentanone & & & 6,975 & 21.2 \\
\hline Butanoic acid & & & 3,130 & 6.3 \\
\hline Acetoin & & & 300,760 & 17.3 \\
\hline Ethylbutyrate & & & 54 & 36.2 \\
\hline Undecane 5,5-dimethyl & & & 997 & 41.3 \\
\hline Pentamethylheptane & & & 416 & 18.1 \\
\hline Limonene & & & 696 & 53.6 \\
\hline 2-Heptanone & & & 13,425 & 5.3 \\
\hline Hexanoic acid & & & 1,782 & 15.2 \\
\hline Ethylcaproate & & & 2,072 & 168.6 \\
\hline 2-Nonanone & & & 3,403 & 22.3 \\
\hline Octanoic acid & & & 4,528 & 31.3 \\
\hline Ethyloctanoate & & & 50 & 9.9 \\
\hline
\end{tabular}

${ }^{1} \mathrm{n}=$ number of biological replicates analyzed.

${ }^{2} \mathrm{ND}=$ not detectable

well. For Cheddar, the process required refinement, because the salt is added before the last centrifugation step, after which excess whey is still being removed, leading to an additional reduction of sodium chloride during this step. This reduction was compensated for by increasing the initial amount of sodium chloride added. The analysis of our cheeses showed a $\mathrm{NaCl}$ concentration of $3.0 \%( \pm 0.1)$ and $2.9 \%( \pm 0.3)$ (in $\mathrm{DM})$ for Gouda- and Cheddar-type cheese, respectively.

The average fat content in dry matter was measured in pooled Gouda-type microcheeses and was determined to be $40.2 \%( \pm 0.4)$, which is considerably lower than the $48 \%$ measured in industrial cheese manufactured with the same standardized milk. Based on these results, the fat loss for Gouda-type cheese in the microcheese system was estimated to be approximately $19.0 \%( \pm 0.4)$, which is significantly higher than the $7 \%$ normally observed in industrially manufactured cheeses. Similarly, an increased fat loss of $16.2 \%( \pm 1.3)$ was observed with the Cheddar-type protocol. The enhanced fat loss in the microcheese system is most likely due to the small curd size and the centrifugation steps in our protocol, which favor phase separation. To assess the influence of the lower fat content on the cheese microstructure, CLSM images were generated for 3 individually manufactured microcheeses, and compared with industrially produced Gouda-type cheese. The CSLM images obtained for microcheese samples were similar to those obtained with industrially made Gouda-type cheese (Figure 4). Coalescence of the fat globules was clearly present in the microcheese model system, indicating a similar microstructure of the 2 sample types. These 

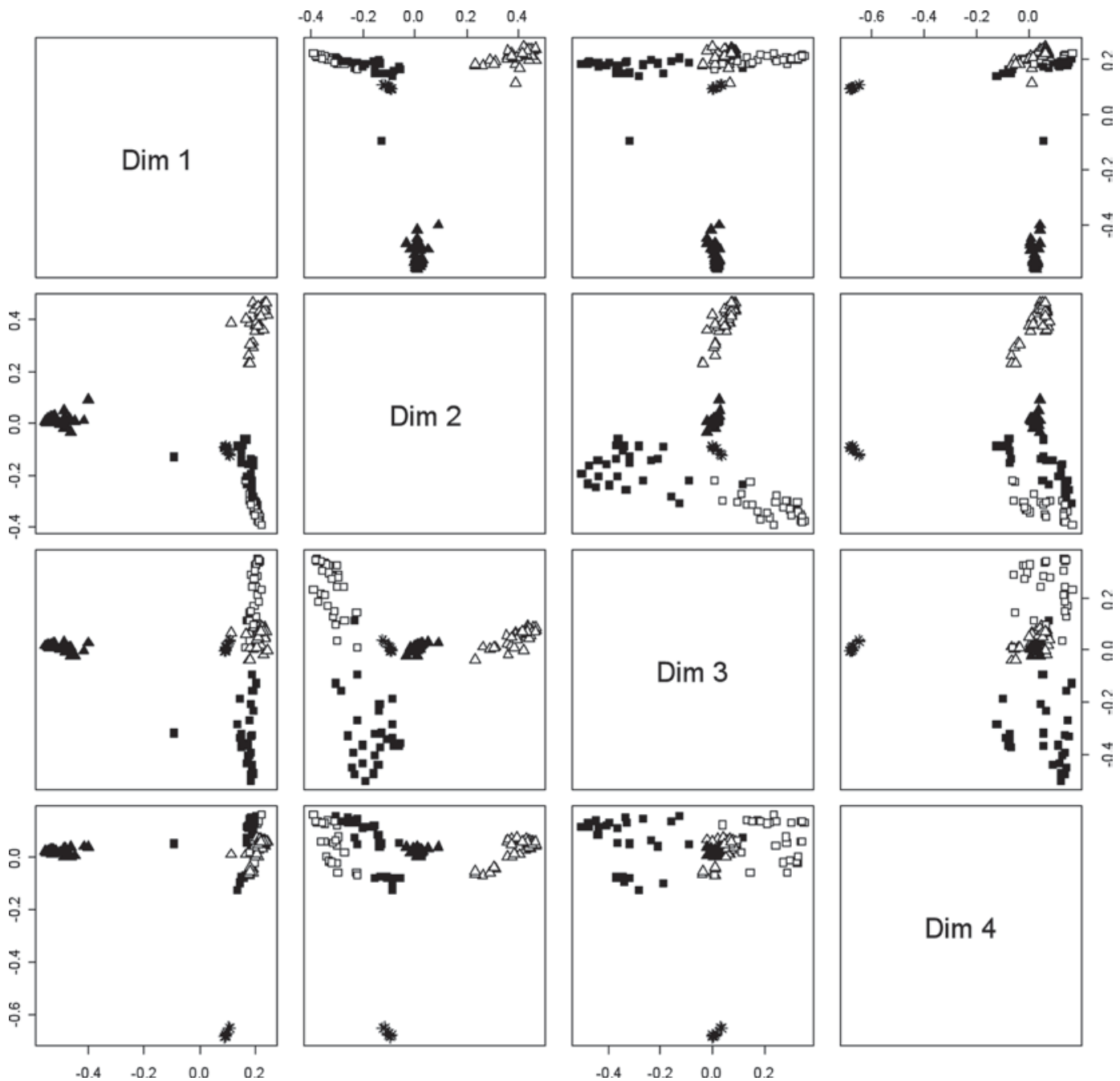

Figure 5. Multidimensional (Dim = dimension) scaling plot of GC-MS peak areas (Table 2) of volatile compounds measured in microcheese after $42 \mathrm{~d}$ of cheese ripening. The analysis is based on supervised random forest, and the results allow distinguishing of 4 different types of microcheese and industrially manufactured cheese. Gouda without adjunct (FR18, $\square$ ), Gouda with adjunct (FR18-APS, $\mathbf{}$ ), Cheddar without adjunct $(\mathrm{RA} 21, \Delta)$, Cheddar with adjunct $(\mathrm{RA} 21-\mathrm{FLAV} 54, \mathbf{\Delta})$, and industrially manufactured Gouda (Jonge Beemster, $\left.{ }^{*}\right)$.

findings illustrate the fact that, despite the lower relative fat content in the microcheese compared with the industrial cheese, the structural properties observed in terms of fat coalescence are conserved.

\section{Volatile Metabolites}

To further compare the microcheeses with industrially manufactured cheese, the levels of flavor volatiles were determined in microcheeses using a high-throughput GC-MS setup. Typical cheese flavor compounds could be detected, including acetic acid, acetoin, butanoic acid, diacetyl, ethylbutyrate, ethylhexanoate, ethyloctanoate, 3-methylbutanal, hexanoic acid, limonene, 2-nonanon, pentanone, pentenal, and 2-propanon (Table 2 ). The areas under all identified peaks were used as a measure to quantify the flavor compounds, and quantified data were subjected to detailed statistical analysis. A multidimensional scaling plot showed that the replicate microcheese samples clustered closely together and that the 4 different types of cheese (Gouda- and Cheddar-types with and without adjunct culture) could be clearly distinguished (Figure 5). Consequently, a full random forest classifier (classifying both ripening periods and starter compositions) based on the compound data showed a low out-of-box prediction error estimate of approximately $5 \%$. Similarly, the difference between samples with either 7 or $42 \mathrm{~d}$ ripening time could be detected with high significance. In general, the samples ripened for $42 \mathrm{~d}$ contained higher concentrations of most flavor compounds, which is consistent with the literature (Roginski, 2003). No significant differences 

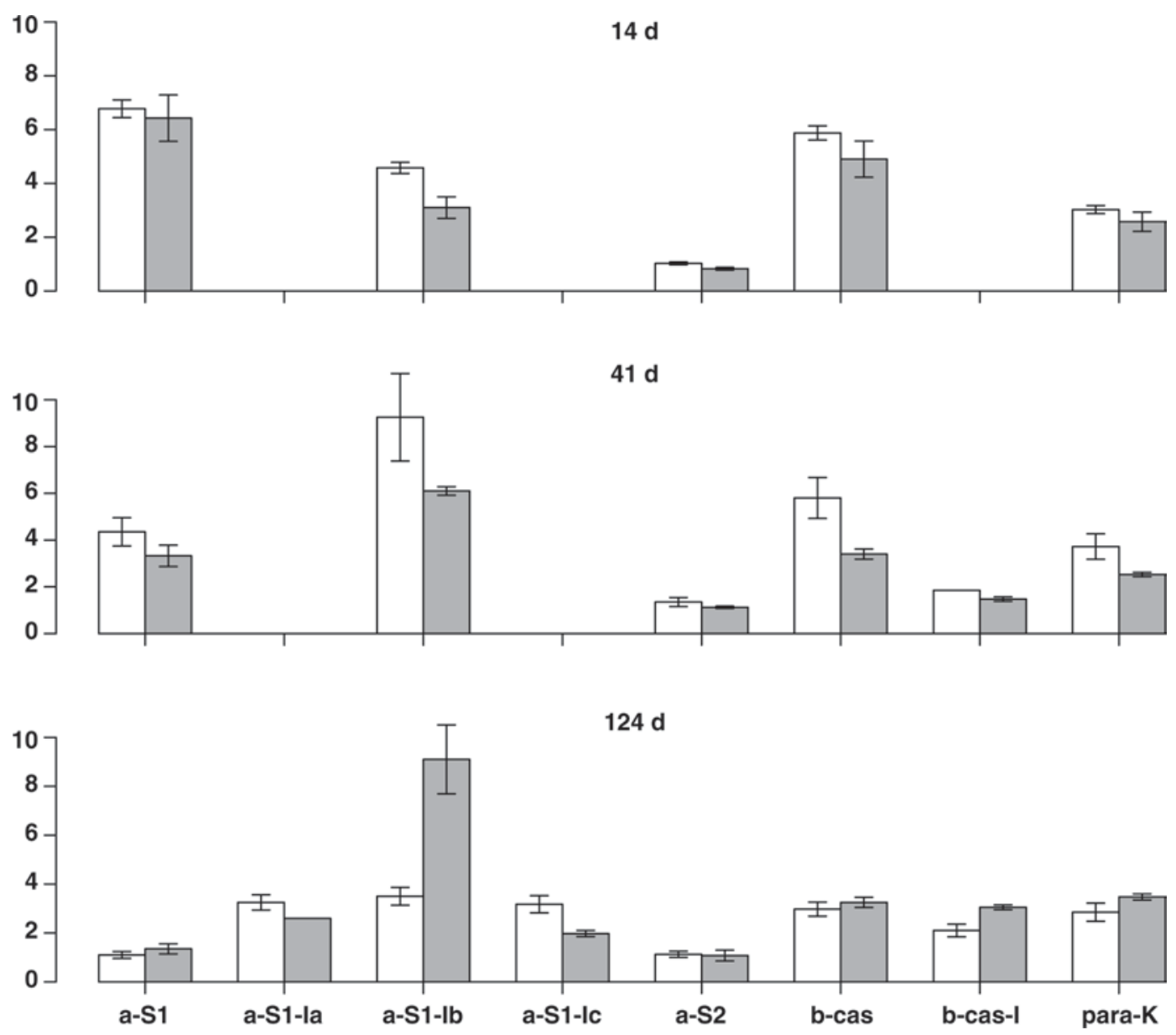

Figure 6. Proteolysis in microcheese and industrially manufactured cheese as determined by reverse phase-HPLC. The levels of various casein fractions and their degradation products are shown. Industrially manufactured cheeses (white bars) are compared with microcheeses (gray bars). The 3 panels represent 14, 41, and $124 \mathrm{~d}$ of ripening time from top to bottom, respectively. Missing bars indicate that those peptides were not detectable. The identified peptides are indicated on the $\mathrm{x}$-axis and the peak areas are indicated on the y-axis. Error bars show standard deviation $(\mathrm{n}=4)$. Fragments $\mathrm{a}_{\mathrm{S} 1}-\mathrm{Ia}, \mathrm{a}_{\mathrm{S} 1}-\mathrm{Ib}$, and $\mathrm{a}_{\mathrm{S1}}-\mathrm{Ic}$ are degradation products of $\alpha_{\mathrm{S}_{1}}$-casein; fragment b-cas-I is a degradation product of $\beta$-casein. With the exception of peptide $\alpha_{\mathrm{S}_{1}}-1 \mathrm{~b}$, the protein degradation in the 2 types of cheese is very similar.

were detected for the same type of microcheeses produced on different days. Flavor profiles of a control sample (Jonge Beemster) used in the GC-MS analysis confirm the global resemblance between microcheese and industrial cheese, yet these profiles allowed us to distinguish all analyzed cheeses (Figure 5). Furthermore, Gouda-type microcheeses manufactured with the APS adjunct culture showed many similarities to their industrially manufactured counterpart, Proosdij-type cheese (Neeter et al., 1996).

\section{Bacterial Growth and Survival}

The number of bacterial colony-forming units per gram of microcheese manufactured with a Gouda-type protocol was determined 2 and $27 \mathrm{~d}$ after the cheeses were produced, and approximately $2 \times 10^{9} \mathrm{cfu}$ and $1 \times$
$10^{8} \mathrm{cfu}$ per gram of cheese were recovered after 2 and $27 \mathrm{~d}$ of cheese ripening, respectively. These results are comparable to the counts detected in industrial cheeses (Ayad et al., 2000, 2001).

\section{Comparison of Microcheese and Industrial Cheese}

To obtain a direct comparison between traditionally manufactured cheese and the microcheese model, the same raw materials were used for manufacturing both types of cheese with the same specifications. Based on previously published information (Exterkate et al., 2001), RP-HPLC analysis of microcheese and industrial cheese samples allowed the identification of individual peptide fragments (Figure 6). In both types of cheese, the $\alpha_{\mathrm{S1}^{-}}, \alpha_{\mathrm{S}^{-}}, \beta$-casein, and para- $\kappa$-casein fractions were present at similar levels and their changes over 


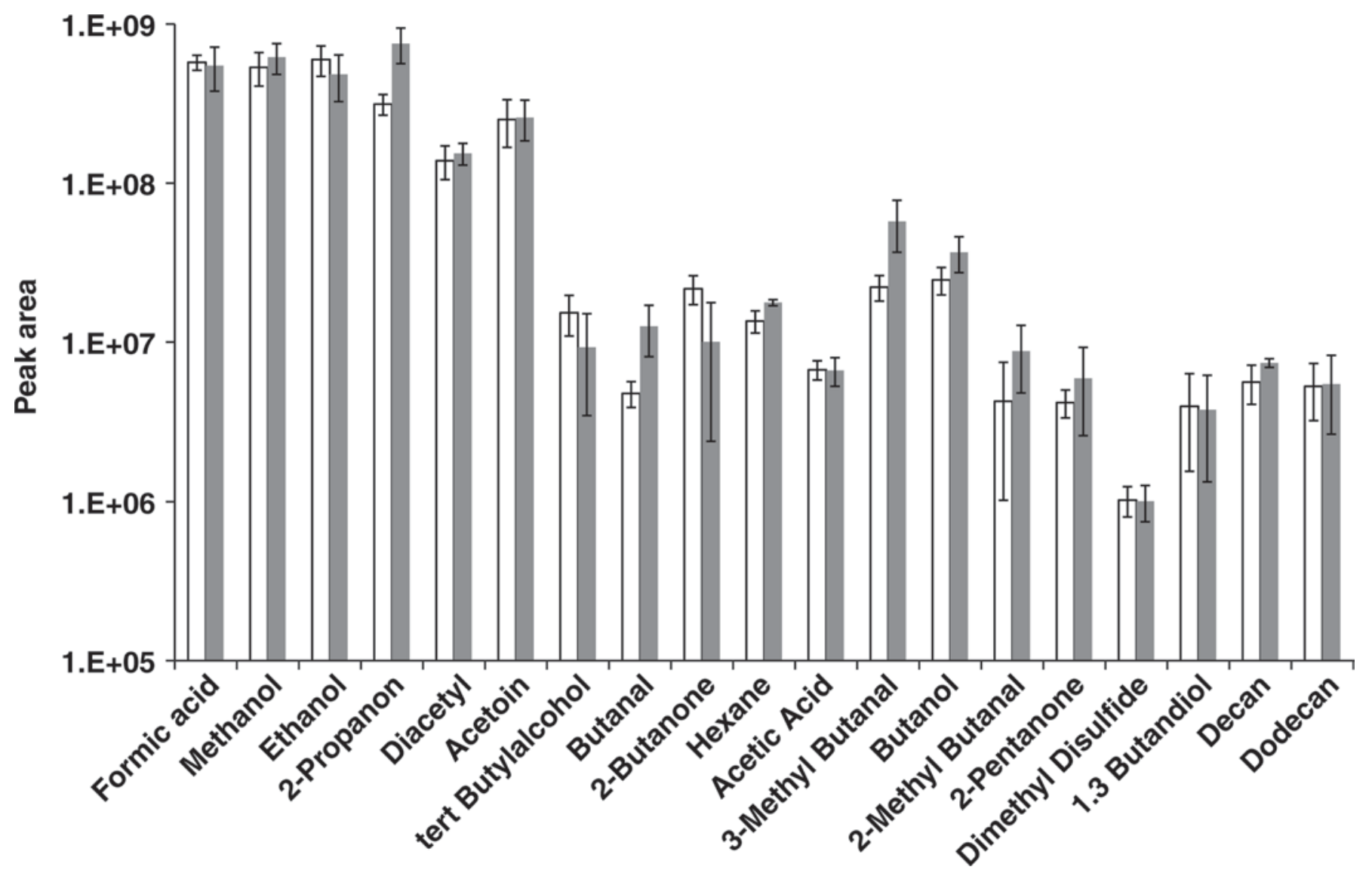

Figure 7. Quantification of volatile flavor compounds as measured in a conventionally produced cheese (white bars) and microcheese (gray bars) after $41 \mathrm{~d}$ of ripening. Error bars show standard deviation $(\mathrm{n}=5)$. The identified compounds are given on the $\mathrm{x}$-axis and peak areas are given on the y-axis. Overall, the data obtained from microcheese and industrial cheese show good correlation.

time were in good agreement. Their degradation products, $\alpha_{\mathrm{S} 1}-\mathrm{Ia}, \alpha_{\mathrm{S1}}$-Ic, and $\beta$-casein-I, were also in very good agreement between the 2 types of cheese at all ripening times. The only difference detected between the RP-HPLC profiles was the appearance of the $\alpha_{\mathrm{S} 1}-\mathrm{Ib}$ fraction, which was increased after $41 \mathrm{~d}$ of ripening and decreased after $124 \mathrm{~d}$ of ripening in industrial cheese compared with microcheese. This suggests a higher turnover rate of this peptide in industrial cheese. In addition to the clearly identifiable peaks, the overall comparison of the samples of both cheeses yielded very similar elution profiles (data not shown). Taken together, the detected time-dependent degradation of milk proteins is similar in both types of cheese and consistent with the literature (Visser, 1993).

Flavor compounds were quantified by determining peak areas of GC-MS analysis (Figure 7). The overall correlation coefficients (R) for the 14-, 41-, and 124-dold samples were calculated to be $0.95,0.97$, and 0.92 , respectively. Small differences were measured for the short-chain aldehydes butanal, 3-methylbutanal, and 2-methylbutanal, which were 2.6-, 2.6-, and 2.1-fold higher, respectively, in microcheese compared with conventional cheese (Figure 7). In addition, 2-propanone appeared to be present at a higher level in microcheese, whereas 2-butanon levels were higher in conventional cheese. All other compounds measured (e.g., diacetyl, acetoin, butanol, 2-pentanone, and dimethyl-disulfide) displayed a very good quantitative correlation between the 2 cheeses.

Overall, using exactly the same raw materials, the microcheese model system generated similar results compared with industrial cheese over extended ripening times, exemplifying the suitability of the model system for screening purposes with good up-scaling extrapolation characteristics.

\section{MetC and BcKAD Overproducers as Adjunct Cultures}

To further investigate the starter culture screening potential offered by the microcheese model, the effect 
of the addition of selected adjunct starter cultures in the Gouda-type microcheese was evaluated. The use of an adjunct culture that overproduced MetC and its cognate deletion mutants resulted in no significant differences in flavor profiles (data not shown). These results are consistent with data obtained from industrial cheese, where sensory analysis revealed no effect by overexpressing MetC [P. Bruinenberg (DSM Food Specialties, Delft, the Netherlands), J. A. Wouters, M. Twigt, J. Muller-Beenhakkers, T. Jansen-van den Bosch, G. Rutten, (all NIZO Food Research, Ede, the Netherlands), R. van Kranenburg (Purac, Gorinchem, the Netherlands), G. Smit (Unilever Food and Health, Vlaardingen, the Netherlands), and J. E. T. van Hylckama Vlieg (Danone Research, Palaiseau Cedex, France; unpublished data). Moreover, Gouda-type microcheeses were manufactured using strain L. lactis B1157 as an adjunct culture. This strain is known to express high levels of the BcKAD enzyme, which is known to catalyze the formation of aldehydes from $\alpha$-keto-acids (Smit et al., 2005a). The ability of strain B1157 to form relatively high concentrations of 3-methylbutanal was established in a laboratory medium (Smit et al., 2005a) as well as in a cheese model system (Ayad et al., 1999) and in industrially manufactured cheese (Ayad et al., 2000). In addition, microcheeses were manufactured containing adjunct culture B2083, a B1157 derivative in which the $b c k a d$ gene has been inactivated or a genetically engineered strain (NZ9000-pNZ7500), and where BcKAD is expressed at a high level after induction of the nisincontrolled expression system (Smit et al., 2005a). After $41 \mathrm{~d}$ of cheese ripening, microcheeses produced with strains B1157 and NZ9000-pNZ7500 cultures contained 7.6- and 5.3-fold increased 3-methylbutanal levels, respectively, compared with the control microcheeses (Figure 8). Both differences are highly significant $(P<$ 0.001 ) and are consistent with differences observed in cheeses produced with the same cultures on an industrial scale (Ayad et al., 2000). These findings demonstrate that the microcheese model allows the accurate prediction of the flavor profile effect of modulation of a single enzyme in the starter culture, both for enzymes that generate a flavor effect as well as enzymes that do not. Therefore, these results underline the advanced predictive value of the microcheese model compared with liquid culture screening results, which suggested that MetC overproduction might affect cheese flavor profiles (Fernandez et al., 2000).

\section{DISCUSSION}

Here we describe a high-throughput cheese-manufacturing model, which was benchmarked against industrially manufactured cheese. The results demonstrate that

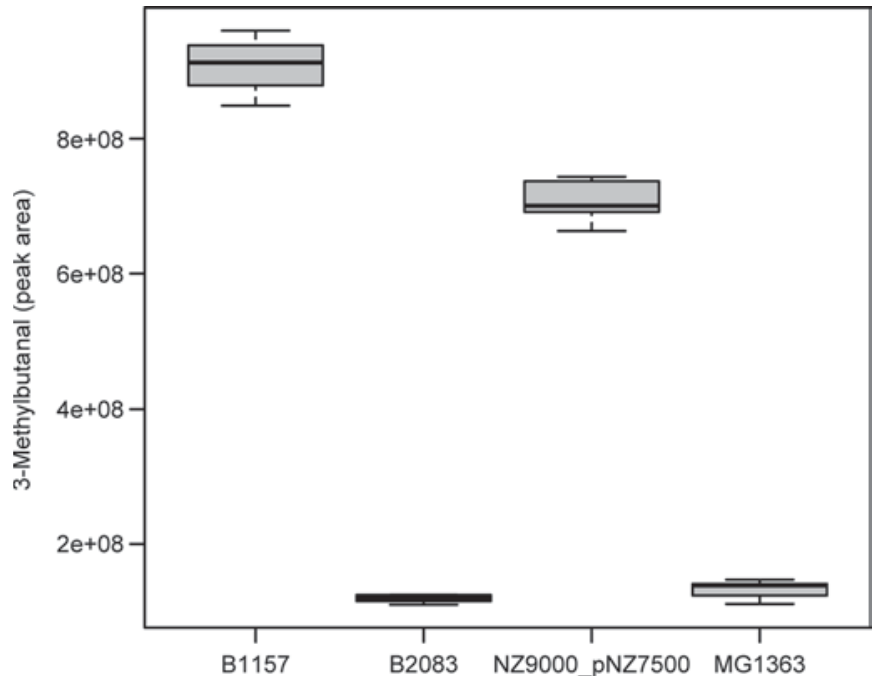

Figure 8. Gouda microcheese production with (engineered) adjuncts, high in 3-methylbutanal production, and the isogenic control strains. Peak areas of 3-methylbutanal concentrations as measured after $41 \mathrm{~d}$ of ripening. The indicated strains are Lactococcus lactis B1157 ( $\mathrm{n}=4)$; a derivative with an inactivated branched-chain $\alpha$-keto acid decaboxylase (bckad) gene B2083 $(\mathrm{n}=5)$; a bckad overexpression strain NZ9000 pNZ7500 $(\mathrm{n}=5)$; and a corresponding control strain MG1363 $(\mathrm{n}=5)$. Whiskers show the total range of measured values. The boxes show the median and the 25 th and 75 th percentiles.

the physicochemical parameters of microcheese closely resemble those of industrial cheese and show high reproducibility between individually manufactured microcheeses. Undoubtedly, key parameters measured in relation to the suitability of the microcheese model for screening purposes is the determination of proteolytic and volatile metabolite profiles during cheese ripening. Many aspects of the degradation pattern of milk proteins in the microcheese model were highly similar to industrially produced cheese (Figure 7). Furthermore, clear parallels were observed in profiles of time-dependent production of volatile flavor compounds during cheese ripening in microcheeses and industrial cheeses. The Gouda-type microcheese produced with the APS adjunct culture resembled the commercially produced Proosdij-type cheese, which has been extensively characterized (Neeter et al., 1996; Ayad et al., 2003). Volatile compounds such as 2-propanon, acetoin, diacetyl, acetic acid, 3-methylbutanal, 2-pentanone, ethylbutyrate, limonene, hexanoic acid, 2-nonanone, 2-heptanone, and ethylcaproate were found in microcheeses as well as in their industrial counterparts (Neeter et al., 1996). Microcheese samples were obtained after 7 and $42 \mathrm{~d}$ of ripening and an increase of all of the above compounds during the ripening period was identified, which can be compared with the described flavor development in industrially produced cheese (Neeter et al., 1996). The influence of the APS adjunct culture on Gouda- 
type cheese flavor profiles is subtle and the difference in taste is partially determined by the ratios of different volatile compounds to each other. The statistical analysis of microcheeses manufactured with and without APS adjunct allowed us to distinguish the 2 types of cheese. One of the key flavor compounds known to play an important role in the flavor of Proosdij-type cheese is 3-methylbutanal. In agreement with results from industrial cheeses (Neeter et al., 1996), we found increased concentrations of 3-methylbutanal in microcheese manufactured with the APS adjunct culture. However, this difference was much more pronounced in 1-wk-old microcheeses (2.9-fold increase with APS) than in 6-wk-old microcheeses (1.2-fold increase with APS). Such a decrease of 3-methylbutanal with ripening time has been observed before in industrially manufactured cheese and it is speculated that this decrease is caused by the conversion of the aldehyde to the corresponding alcohol (Ayad et al., 2003). For the production of Cheddar-type microcheese, commercially available starter cultures were used. The Cheddar adjunct culture used is known to enhance the sweet note of cheese. The most distinguished difference caused by the Cheddar adjunct Flav54 in the microcheese system was a significant increase in the concentration of acetic acid (4.1-fold). Increased concentrations of acetic acid were correlated to the sweetness of cheese (Biede and Hammond, 1979), which would be consistent with our findings. Moreover, the predictive value of flavor volatile patterns obtained from the microcheese model was established by a direct comparison of the model with the normal cheese production process, using the same raw materials, which was further confirmed by the designed manipulation of the 3-methylbutanal levels using engineered adjunct starter cultures (Smit et al., 2005a; Figures 7 and 8).

The obvious and unavoidable differences between the 2 systems used are the smaller curd size and the larger volume:surface ratio, which cause some of the differences observed between the 2 systems, including the decreased fat content in the microcheese model and the slight deviations in flavor profiles. Nevertheless, despite the lower fat content, the microstructure of the microcheeses was comparable to that of industrially produced cheese.

Taken together, our data support the conclusion that the microcheeses manufactured in a high-throughput format resemble most key properties of conventionally manufactured cheese. The data show that the microcheese model offers a potential high-throughput system for a variety of screening purposes. Therefore, current activities focus on (further) automation of the described protocol to enhance its throughput and improve, for example, the reproducibility of stirring intensities.
The protocols will be extended to additional cheese types such as Emmental and soft cheeses. In addition to offering a valuable screening platform for cheese product development, the model also enables the effective investigation of fundamental questions related to cheese manufacturing and in situ bacterial physiology and genetics. In relation to the latter we have recently developed an improved recombinant in vivo expression technology (R-IVET) system in L. lactis (Bachmann et al., 2008), which has been applied to monitor real-time in situ L. lactis gene expression in individual microcheeses using luciferase as a reporter (Bachmann et al., 2009).

Based on the unprecedented throughput offered by the microcheese model, a range of microbial screening possibilities can be foreseen, including the screening of microbial culture collections for desired flavor-forming capacities, the screening of bacterial mutant libraries, the assessment of microbial viability during the ripening process, and the expression of relevant enzyme activities in situ. In addition, the model appears suitable for the evaluation of variations in processing conditions, the addition of enzymes, and so on. Finally, any of these screening approaches may readily be combined with altered and desired physicochemical parameters of the cheese matrix, such as the reduction of the fat or salt content of cheese, which may offer avenues for the identification of dedicated starter cultures or enzymes able to compensate for flavor and texture defects in these novel cheese matrices.

\section{ACKNOWLEDGMENTS}

We thank Jan van Riel, Jildert Bruinsma, and Patrick Jansen for GC-MS analysis, Jan Klok for CSLM microscopy, Jan de Wit for moisture, salt and fat determinations, Durrita Allersma for cheese manufacturing in the NIZO pilot plant, and Charles Slangen for HPLC analysis. Furthermore, we thank Wim Engels, Eva Düsterhöft, Wim van Ginkel, Frank de Bok, and Jean Banks (all from NIZO Food Research, the Netherlands) for fruitful discussions. We are also grateful to CSK Food Enrichment and Danisco for supplying industrial starter cultures used in this study. This project was carried out within the research program of the Kluyver Centre for Genomics of Industrial Fermentation, which is part of The Netherlands Genomics Initiative/Netherlands Organization for Scientific Research.

\section{REFERENCES}

Ayad, E. H. E., A. Verheul, P. Bruinenberg, J. T. M. Wouters, and G. Smit. 2003. Starter culture development for improving the flavour of Proosdij-type cheese. Int. Dairy J. 13:159-168.

Ayad, E. H. E., A. Verheul, C. d. Jong, J. T. M. Wouters, and G. Smit. 1999. Flavour forming abilities and amino acid requirements 
of Lactococcus lactis strains isolated from artisanal and non-dairy origin. Int. Dairy J. 9:725-735.

Ayad, E. H. E., A. Verheul, J. T. M. Wouters, and G. Smit. 2000. Application of wild starter cultures for flavour development in pilot plant cheese making. Int. Dairy J. 10:169-179.

Ayad, E. H. E., A. Verheul, J. T. M. Wouters, and G. Smit. 2001 Population dynamics of lactococci from industrial, artisanal and non-dairy origins in defined strain starters for Gouda-type cheese. Int. Dairy J. 11:51-61.

Azarnia, S., N. Robert, and B. Lee. 2006. Biotechnological methods to accelerate cheddar cheese ripening. Crit. Rev. Biotechnol. $26: 121-143$.

Bachmann, H., L. De Wilt, M. Kleerebezem, and J. E. van Hylckama Vlieg. 2008. Gene expression of Lactococcus lactis during the fermentation of cheese. In 9th Symposium on Lactic Acid Bacteria. FEMS, Egmond aan Zee, the Netherlands.

Bachmann, H., M. Kleerebezem, and J. E. van Hylckama Vlieg. 2008. High-throughput identification and validation of in situ-expressed genes of Lactococcus lactis. Appl. Environ. Microbiol. 74:47274736 .

Bachmann, H., M. J. Starrenburg, A. Dijkstra, D. Molenaar, M. Kleerebezem, J. L. Rademaker, and J. E. van Hylckama Vlieg. 2009. Regulatory phenotyping reveals important diversity within the species Lactococcus lactis. Appl. Environ. Microbiol. 75:56875694.

Biede, S. L., and E. G. Hammond. 1979. Swiss cheese flavor: II. Organoleptic analysis. J. Dairy Sci. 62:238-248.

Brandsma, J. B., E. Floris, A. R. D. Dijkstra, L. Rijnen, J. A. Wouters, and W. C. Meijer. 2008. Natural diversity of aminotransferases and dehydrogenase activity in a large collection of Lactococcus lactis strains. Int. Dairy J. 18:1103-1108.

Breiman, L. 2001. Random Forests. Mach. Learn. 45:5-32.

Crow, V. L., R. Holland, G. G. Pritchard, and T. Coolbear. 1994. The diversity of potential cheese ripening characteristics of lactic acid starter bacteria: 2. The levels and subcellular distributions of peptidase and esterase activities . Int. Dairy J. 4:723-742.

El Soda, M., S. A. Madkor, and P. S. Tong. 2000. Adjunct cultures: Recent developments and potential significance to the cheese industry. J. Dairy Sci. 83:609-619.

Exterkate, F. A., C. Slangen, and R. J. Siezen. 2001. Effect of genetically modified Lactococcus lactis cell-envelope proteinases with altered specificity on the course of casein degradation under cheese conditions. Int. Dairy J. 11:363-371.

Fernandez, M., W. van Doesburg, G. A. Rutten, J. D. Marugg, A. C. Alting, R. van Kranenburg, and O. P. Kuipers. 2000. Molecular and functional analyses of the metC gene of Lactococcus lactis, encoding cystathionine beta-lyase. Appl. Environ. Microbiol. $66: 42-48$.

Fox, P. F., and J. M. Wallace. 1997. Formation of flavor compounds in cheese. Adv. Appl. Microbiol. 45:17-85.

Fox, P. F., J. M. Wallace, S. Morgan, C. M. Lynch, E. J. Niland, and J. Tobin. 1996. Acceleration of cheese ripening. Antonie Van Leeuwenhoek 70:271-297.

Gasson, M. J. 1983. Plasmid complements of Streptococcus lactis NCDO 712 and other lactic streptococci after protoplast-induced curing. J. Bacteriol. 154:1-9.

Hassan, A. N., S. Awad, and K. Muthukumarappan. 2005. Effects of exopolysaccharide-producing cultures on the viscoelastic properties of reduced-fat Cheddar cheese. J. Dairy Sci. 88:4221-4227.

Kammerlehner, J. 1989. Lab-Kaese Technologie Band III. Molkereitechnik Band 84/85. Verlag Th. Mann, GelsenkirchenBuer, Germany.

Kuipers, O. P., P. G. G. A. de Ruyter, M. Kleerebezem, and W. M. de Vos. 1998. Quorum sensing-controlled gene expression in lactic acid bacteria. J. Biotechnol. 64:15-21.

Ledeboer, A. M., S. Bezemer, J. J. de Hiaard, I. M. Schaffers, C. T. Verrips, C. van Vliet, E. M. Dusterhoft, P. Zoon, S. Moineau, and L. G. Frenken. 2002. Preventing phage lysis of Lactococcus lactis in cheese production using a neutralizing heavy-chain antibody fragment from llama. J. Dairy Sci. 85:1376-1382.

Lucey, J. A., M. E. Johnson, and D. S. Horne. 2003. Invited review: Perspectives on the basis of the rheology and texture properties of cheese. J. Dairy Sci. 86:2725-2743.

Malo, N., J. A. Hanley, S. Cerquozzi, J. Pelletier, and R. Nadon. 2006. Statistical practice in high-throughput screening data analysis. Nat. Biotechnol. 24:167-175.

McSweeney, P. L. H., and M. José Sousa. 2000. Biochemical pathways for the production of flavour compounds in cheeses during ripening: A review. Lait 80:293-324.

Neeter, R., C. De Jong, H. G. J. Teisman, and G. Ellen. 1996. Determination of volatile components in cheese using dynamic headspace techniques. Pages 293-296 in Flavour science: Recent developments. O. S. M. A. J. Taylor, ed. Royal Society of Chemistry., London.

R-Development Core Team. 2008. R: A Language and Environment for Statistical Computing. R Foundation for Statistical Computing, Vienna, Austria.

Roginski, H. 2003. Encyclopedia of Dairy Sciences. H. Roginski, J. W. Fuquay, and P. F. Fox, ed. Academic Press, Elsevier Science Ltd., San Diego, CA.

Shakeel-Ur-Rehman, , P. F. Fox, P. L. H. McSweeney, S. A. Madkor, and N. Y. Farkye. 2001. Alternatives to pilot plant experiments in cheese-ripening studies. Int. J. Dairy Technol. 54:121-126.

Shakeel-Ur-Rehman, , P. L. H. McSweeney, and P. F. Fox. 1998. Protocol for the manufacture of miniature cheeses. Lait 78:607620 .

Simal, S., E. S. Sánchez, J. Bon, A. Femenia, and C. Rosselló. 2001. Water and salt diffusion during cheese ripening: Effect of the external and internal resistances to mass transfer. J. Food Eng. 48:269-275.

Smit, B. A., W. J. Engels, J. Bruinsma, J. E. van Hylckama Vlieg, J. T. Wouters, and G. Smit. 2004. Development of a high throughput screening method to test flavour-forming capabilities of anaerobic micro-organisms. J. Appl. Microbiol. 97:306-313.

Smit, B. A., J. E. van Hylckama Vlieg, W. J. Engels, L. Meijer, J. T. Wouters, and G. Smit. 2005a. Identification, cloning, and characterization of a Lactococcus lactis branched-chain alpha-keto acid decarboxylase involved in flavor formation. Appl. Environ. Microbiol. 71:303-311.

Smit, G., B. A. Smit, and W. J. Engels. 2005b. Flavour formation by lactic acid bacteria and biochemical flavour profiling of cheese products. FEMS Microbiol. Rev. 29:591-610.

van Kranenburg, R., M. Kleerebezem, J. van Hylckama Vlieg, B. M. Ursing, J. Boekhorst, B. A. Smit, E. H. E. Ayad, G. Smit, and R. J. Siezen. 2002. Flavour formation from amino acids by lactic acid bacteria: Predictions from genome sequence analysis. Int. Dairy J. 12:111-121.

Van Slyke, L. L., and W. V. Price. 1949. Cheese. Orange Judd Publ. Co. Inc., New York, NY.

Visser, S. 1993. Proteolytic enzymes and their relation to cheese ripening and flavor: An overview. J. Dairy Sci. 76:329-350.

Visser, S., C. J. Slangen, and H. S. Rollema. 1991. Phenotyping of bovine milk proteins by reversed-phase high-performance liquid chromatography. J. Chromatogr. A 548:361-370.

Yvon, M., E. Chambellon, A. Bolotin, and F. Roudot-Algaron. 2000. Characterization and role of the branched-chain aminotransferase (BcaT) isolated from Lactococcus lactis subsp. cremoris NCDO 763. Appl. Environ. Microbiol. 66:571-577.

Yvon, M., and L. Rijnen. 2001. Cheese flavour formation by amino acid catabolism. Int. Dairy J. 11:185-201.

Yvon, M., S. Thirouin, L. Rijnen, D. Fromentier, and J. C. Gripon. 1997. An aminotransferase from Lactococcus lactis initiates conversion of amino acids to cheese flavor compounds. Appl. Environ. Microbiol. 63:414-419. 